\title{
Nondestructive Evaluation of Metallic Fillers Embedded in Polyester Matrix
}

\begin{abstract}
ROZINA STEIGMANN ${ }^{1,2}$, ADRIANA SAVIN, NICOLETA IFTIMIE ${ }^{1}$
${ }^{1}$ National Institute of R\&D for Technical Physics,Nondestructive Testing Department, 47 Mangeron Blvd., 700050, lasi, Romania

${ }^{2}$ University Al...Cuza, Faculty of Physics, 11 Carol I Blvd, Iasi, 700506, Romania

Composites made from metallic fillers embedded in polymer matrix have good shielding properties as electrical point of view and tribology properties from mechanical point of view. These properties depend on amounts, shapes, sizes, and combinations of fillers and matrix. This paper proposes an electromagnetic method for determination of metallic fillers concentration in composite materials from metallic fillers embedded in polyester matrix. The bulk resistivity and dielectric permittivity were measured but these measurements are less influenced by the fillers concentration. The amplitude measurement of e.m. finduced in the reception coil of the focalized electromagnetic transducer and their averaging for the scanning of a relative large zone of the composite has proven to be an efficient method. The average amplitude linearly decreases with the increasing of fillers concentration, and has different values for Cu and AISI 316 fillers.
\end{abstract}

Keywords: Polyester, metallic fillers, composite, electromagnetic evaluation, $S$ parameters

Polymer composites materials constitute a very active area for research in material science and nondestructive evaluation. The composites hold improved properties based on the advanced features of each individual component, sustaining new industrial applications which cannot be obtained based on individual components performances [1-3]. It is well known that the thermal and mechanical behavior of polymers is strongly influenced by factors such type, size, content and shape of the fillers [1-3]. Furthermore, these properties have a very complex dependence on the chemical structure and the crosslink density when thermoset resins and metallic fillers are combined $[4,5]$.

Polymer matrix composites containing conductive fillers are interesting for applications as shielding due their processability which helps to reduce or eliminate the seams in the housing that is the shield $[6,7]$. The polymer matrix is commonly electrically insulating and does not contribute to shielding, though the polymer matrix can affect the connectivity of the conductive fillers; this is enhancing the shielding effectiveness. Metallic fillers such as copper, brass, iron, steel, aluminum etc. are added essentially in the various amounts, shapes, sizes, and combinations also in friction materials, [8-10]. These fillers not only improve the thermo-physical properties but also
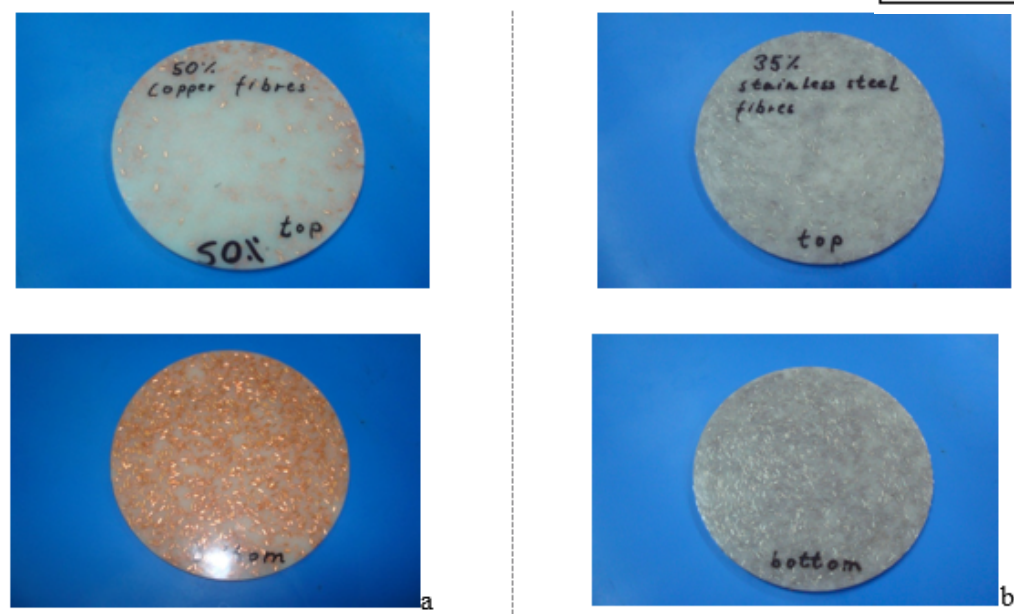

play an important role to enhance the tribo-performance. The use of fillers made from recycled materials increase the energy saving and solve few environmental issues [11].

This paper proposes an electromagnetic method for nondestructive evaluation of fillers concentration in polymer matrix, important feature in applications as construction materials - laminate plates from plasticmetallic fillers (PMF) composites colored by different procedures or friction materials in automotive industry.

\section{Experimental part \\ Studied samples}

Disks from PMF with $125 \mathrm{~mm}$ diameter and $4.5 \mathrm{~mm}$ thickness having the characteristics given in table 1 were taken into study.

The matrix is COLPOLY 7201 polyester, unsaturated resin with addition of styrene in amount up to $50 \%$. Two types of samples are presented in figure 1 .

Table 1

SAMPLE CHARACTERISTICS

\begin{tabular}{|l|c|c|c|}
\hline Metallic fillers & Length [mm] & Diameter [mm] & $\begin{array}{l}\text { Fillers content } \\
\text { [mass \%] }\end{array}$ \\
\hline \multirow{4}{*}{ Copper } & 5 & 1 & 20 \\
\cline { 2 - 4 } & 5 & 1 & 30 \\
\cline { 2 - 4 } & 5 & 1 & 50 \\
\hline \multirow{2}{*}{ AISI 316 } & 5 & 0.4 & 15 \\
\cline { 2 - 4 } & 5 & 0.4 & 35 \\
\hline
\end{tabular}


The fillers have been added by the producer in order to increase the flexural and tensile strength of the laminate [12] to improve thermal transfer during lamination when a considerable exothermic heating can occur, as well as for the increasing the fire resistance of the laminate.

For better characterization and determination of optimum methods for evaluation of fillers content, different types of measurements have been performed.

Bulk resistivity in DC was determined using a $25 \mathrm{kV} D C$ source - HV 350 -AmherstUSA and a picoammeter Keithley 487 USA [13].

The properties in the range of radio frequency were determined by the measurement of $\mathrm{S}$ parameters into a coaxial guide that contains the samples of the composite material, using S Parameter Test Kit 87511A Agilent coupled at Network/Spectrum//mpedance Analyzer 4395A Agilent USA.

In order to minimize the effect of the loss and phase shift in the network between the sample and the measurement reference planes, the length of the $50 \Omega$ sample holder was the same as length of the sample, (fig. 2a). The length of the coaxial sample was $11.6 \mathrm{~mm}$ and the diameter of the inner tube was $3 \mathrm{~mm}$.

Once the $S$ - parameters are known (fig. 22b), the transmission and reflection coefficients $T$ and respective $R$ are computed, leading towards the determination of the electrical permittivity of the composite.

The following set of equations are used [14]

$$
\begin{gathered}
R=k \pm\left(k^{2}-1\right)^{1 / 2} \\
k=\frac{\left(S_{11}^{2}-S_{21}^{2}\right)-1}{2 S_{11}} \\
T=\frac{S_{11}+S_{21}-R}{1-\left(S_{11}+S_{21}\right) R} \\
\varepsilon=\frac{\frac{c}{\omega d} \ln \left(\frac{1}{T}\right)}{\sqrt{\frac{1+R}{1-R}}}
\end{gathered}
$$
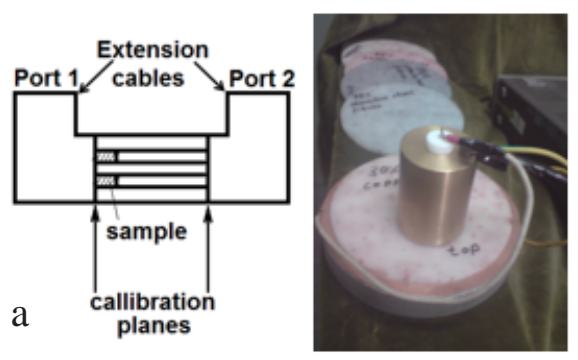
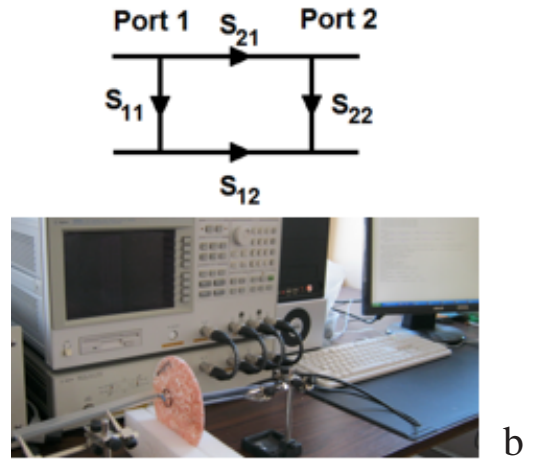

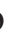

where $c$ is the velocity of light in free space, $\omega$ is the angular frequencyand $d$ is the length of the material sample.

The electromagnetic measurements were effectuated using a special electromagnetic sensor designed in this purpose [15]. The emission part is made from a coil with 50 turns, wound on a ferrite cup core $-18 \mathrm{~mm}$ outer diameter and $5.5 \mathrm{~mm}$ height. The reception coil has 50 turns and is wound perpendicularly on the emission coil.

The transducer is connected to the Network/Spectrum Impedance Analyzer, the relative displacing transducercomposite to be controlled being assured by a $X Y$ motorized stage Newmark USA (fig. 3). The command of equipment and acquisition of data are made by a routine developed in Matlab 2014a.

The determination of metallic fillers concentration by using the information regarding the number of fillers detected by electromagnetic measurement is not realistic due to the relative high number of fillers and their random distribution. Therefore, a more eloquent indicator mightbe the average value of the amplitude of e.m.f. induced in the reception coils of the electromagnetic transducer.

\section{Results and discussions}

In figure 4 is presented the dependency of the electrical resistivity logarithm of composite in function of the fillers concentration, for the two types of fillers considered.

A continuous decrease of the resistivity in function of fillers content can be observed; also a high resistivity is noticed, showing that the percolation does not appear nor at $50 \% \mathrm{Cu}$ fillers concentration. Because the resistivity modifications are small and taking in consideration the simplicity of the measurement method, the processing/ interpretation implies precautions, as this measure cannot constitute an indicator of the filler content.

In figure $5 a$ and $b$ are presented the dependency of the dielectric permittivity (modulus) and the tangent of the loss angle $(\tan \delta)$ by frequency using the methods of the coaxial cable and eqs. (1)-(4).

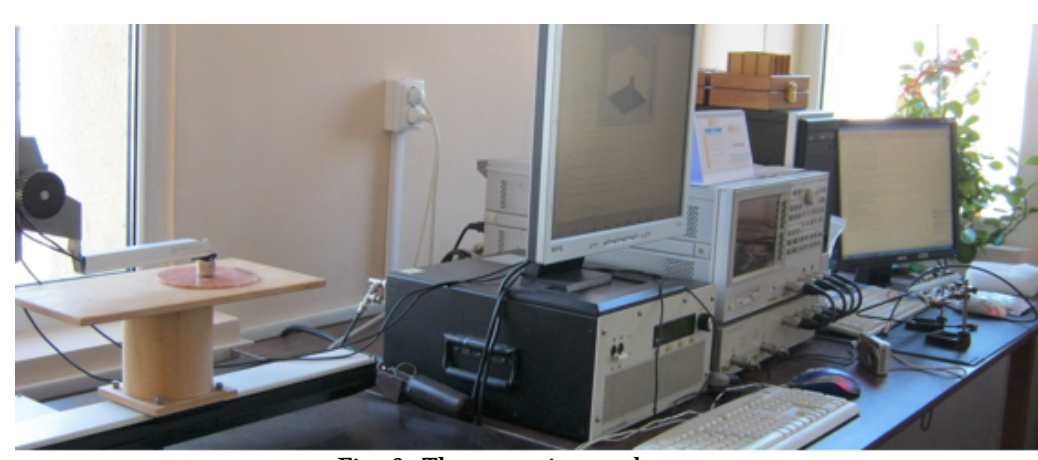

Fig. 3. The experimental set-up

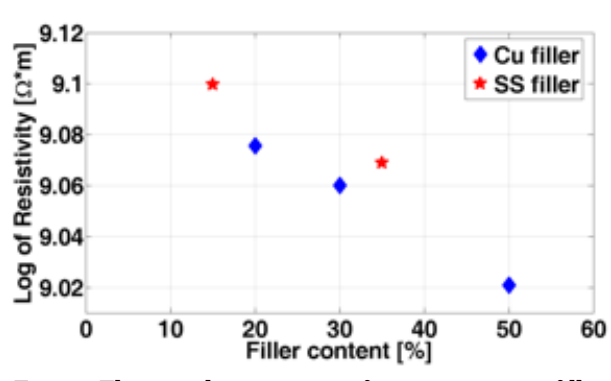

Fig. 4. Electrical resistivity of composite vs filler

$$
\text { content }
$$

Fig. 2. Test fixture: a) scheme and coaxial sample holder; b) S-parameter flow graph and experimental set-up 


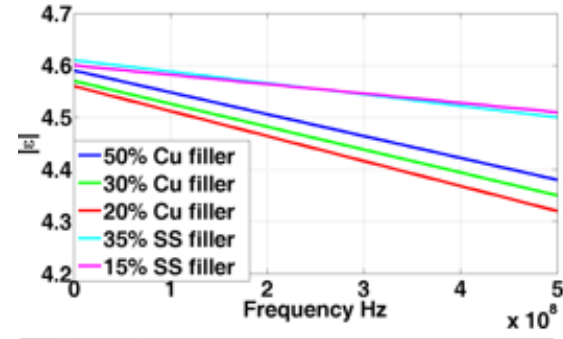

Fig. 5. Dielectric permittivity vs frequency: a) modulus; b) $\tan \delta$

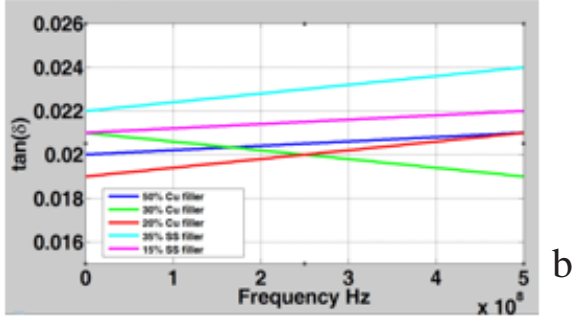

The analysis of data from figure 5 shows a decrease of the permittivity modulus with the frequency, in a linear trend. The permittivity has high values in the case of AISI 316 fillers composite and slightly lower for the Cu fillers. The value of tand is practically constant with the frequency in the range $100 \mathrm{kHz}-500 \mathrm{MHz}$.

The electromagnetic measurements allows the visualization of metallic fillers from the studied composite materials, the resolution being good enough at $2 \mathrm{MHz}$ frequency, as presented in figures $6 a$ and $b$ for the case of cu $50 \%$ fillers content.

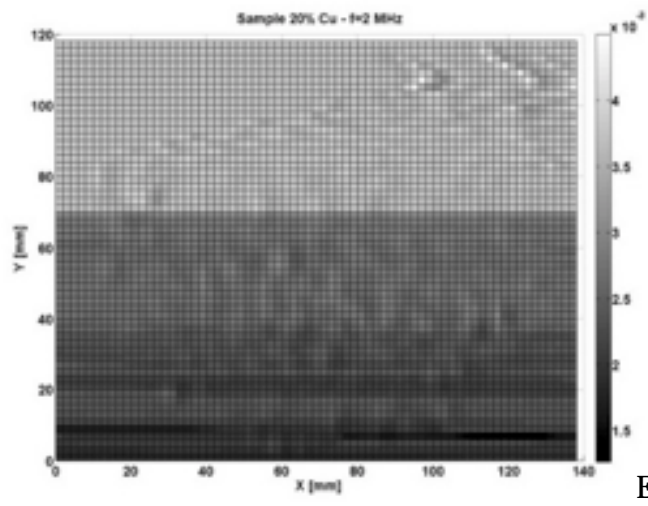

a

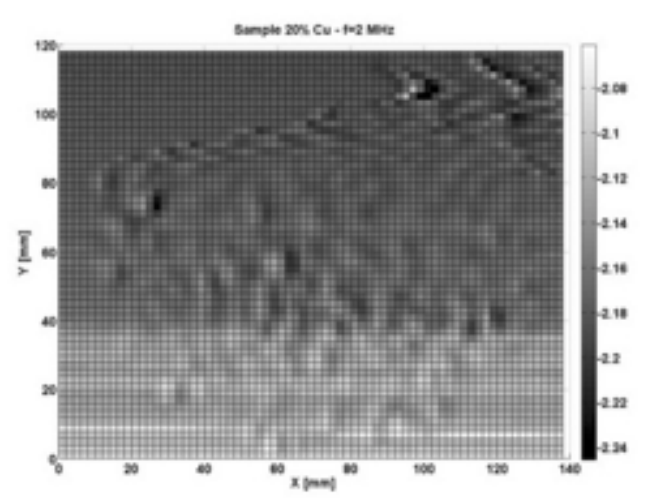

Fig. 6.

Electromagnetic measurement at frequency of

2MHz: a) amplitude; b) phase

b

Even at a thin scan steps (e.g. of $0.2 \mathrm{~mm}$ ), due to the fact that some fillers can be screened by others, the count of fillers is an operation accompanied by large errors; therefore this type of measurements cannot be used as indicator of fillers content in the examined composite.

A much simpler and more efficient method is represented by the mean value of the e.m.f. amplitude induced in the reception coil at a frequency conveniently chosen, when the transducer scans a relatively large area of the composite.

\section{References}

1.BEZNEA, E. F., CHIRICA, I., BAROIU, N., TEODOR, V., Parametric Study of Experimental and Numerical Simulation of Sandwich Composite Structures Flexural Behaviour, Mat. Plast., 54, no. 4, 2017, p. $682-688$

2. CROITORU, E.I., OANCEA, G., CONSTANTIN, N., Impact Testing On

Composite Panels Of Fiberglass, Carbon And Kevlar-Carbon a to the amplitude of e.m.f. induced in the reception coil hen the transducer is placed on a sample of COLPOLY

polyester resin.

coil decreases more rapidly with the increase of the concentration in the case of $\mathrm{Cu}$ filler than in the case of AISI 316 fillers. For fillers concentrations that exceed 70\%, the percolation phenomenon is possible to appear and the

\section{Conclusions} measurements shows that these measures are relatively less influenced by the concentration of $\mathrm{Cu}$ and AISI 316 $5 \mathrm{~mm}$ length. The value of tand practically does not vary ith the filler concentration. transducer allow the visualization of the metallic fillers in composite. Due to the effect of shielding of the neighboring cers, the filler count from the electromagnetic images concentration.

The average value of the amplitude of e.m.f induced in concentration this decreasing with the increasing of the concentration.

Further studies will imply determination of mechanical properties in order to use the composite plastic-metallic

Acknowledgements: This paper is partially supported by Romanian istry of Research and Innovation under Nucleus Program, project PN 18060102 and under UEFISCDI Grant PN-III-P1-1.2-PCCDI-20170239, 60PCCDI 2018 within PNCDI III. 
Comparison and Validation Study, Mat. Plast., 54, no. 4, 2017, p.700707

3.BORDEASU, I., MICU, L. M., MITELEA, I.,UTU, I., D., PIRVULESCU, L, D.,SIRBU, N, A., Cavitation Erosion of HVOF Metal-ceramic Composite Coatings Deposited onto Duplex Stainless Steel Substrate, Mat. Plast., 53, no.4, 2016, p.781-786

4.KLYUCHNIKOVA, N.V., LYMAR, E.A., Glass and Ceramics, 62, no.910, p.319-320, 2005

5.BHATTACHARYA, S.K., Metal filled polymers (properties and applications), M.Dekker, NY, 1986

6.RADHAKRISHNAN, S., SAINI, D. R., Journal of Materials Science, 26(21p5950-5956), 1991

7.CHUNG, D.D.L., J.Mater. Eng. Perf., 9, 3, p. 350-354, 2000

8.BIJWE, J., KUMAR, M., Wear 263, p. 1243-1248, 2007.

9.KUMAR, M., BIJWE, J., Wear 270, p. 269-280, 2011
10.BORDEASU, I., MITELEA, I., LAZAR, I., MICU, L. M., KARANCSI, O., Cavitation Erosion Behaviour of Cooper Base Layers Deposited by HVOF Thermal Spraying, Rev. Chim. (Bucharest), 68, no.12, 2017, pp.2914-2917

11.PARGI, M. N. F., TEH, P. L., HUSSIENSYAH, S., YEOH, C. K., GHANI, S.A., International J ournal of Mechanical and Materials Engineering, 10(1, p.1-10), 2015

12.PARLEVLIET, P. P., BERSEE, H. E. N., BEUKERS, A., Composites, Part A: Applied Science and Manufacturing, 38 (3, p.651-665), 2007 13.*** ASTM D257-78 - DC Resistance and conductance of insulating materials

14.HO, T.Q., LOGAN, J.C., SCHUKANTZ, J.H., SHAW, F.W., WELCH, R.Q., US Navy - Technical Document 2457, 1993

15.GRIMBERG, R., SAVIN, A., RADU, E., MIHALACHE, O., IEEE Transactions on Magnetics, 36, 1, p.299-307, 2000

$\overline{\text { Manuscript received: } 15.01 .2018}$ 